\title{
Las relaciones financieras entre el Estado y las Comunidades Autónomas: dos recientes sentencias del Tribunal Constitucional español (Ss. TC 13/1992, de 6 de febrero y 79/1992, de 28 de mayo) ${ }^{1}$
}

\author{
Carlos I. Aymerich Cano \\ Profesor Ayudante de Derecho Administrativo \\ Universidad de A Coruña
}

Sumario: I. LA JURISPRUDENCIA CONSTITUCIONAL RELATIVA A LAS RELACIONES FINANCIERAS ENTRE EL ESTADO Y LAS CC.AA. II. LA STC 13/1992, DE 13 DE FEBRERO. A) Potestad de gasto estatal y autonomía financiera autonómica. B) La territorialización de las partidas presupuestarias que prevean subvenciones estatales en materias de competencia de las CC.AA. C) Los instrumentos de la territorialización: Los Convenios entre el Estado y las CC.AA. III. LA GESTION AUTONOMICA DE LAS AYUDAS COMUNITARIAS: LA STC 79/1992, DE 28 DE MAYO

\section{LA JURISPRUDENCIA CONSTITUCIONAL RELATIVA A LAS RELACIONES FINANCIERAS ENTRE EL ESTADO Y LAS CO- MUNIDADES AUTONOMAS}

Las Ss. TC 13/1992, de 6 de febrero y 79/1992, de 28 de mayo, abren una nueva etapa en la jurisprudencia constitucional relativa a las relaciones financieras entre los diferentes sujetos que integran el Estado compuesto, fundamentalmente entre las CC.AA. y el Estado.

La jurisprudencia anterior del TC establecía una que podemos considerar bien asentada doctrina acerca de los diferentes aspectos a los que afectan estas relaciones financieras, doctrina impecable que, sin embargo, presenta grandes lagunas en lo que a su aplicación a los casos concretos se refiere ${ }^{2}$, por las excepciones que a sus propias reglas generales prevé el

\footnotetext{
1 Traducción por el autor del original gallego a publicar por la Revista Galega de Administración Pública.

2 Para una exposición y análisis de la misma, consultar, entre otros trabajos, la monografía de M. SÁNCHEZ MORÓN, Subvenciones del Estado y Comunidades Autónomas (Tec-
} 
TC y la generosidad con la que éstas se interpretan. Esta doctrina general viene sistematizada en la S. TC $13 / 1992^{3}$ en los siguientes términos:

a) En cuanto al poder estatal de gasto público y al propio establecimiento de ayudas y subvenciones en materia de competencia de las CC.AA.,

"Que no existe una "competencia subvencional" diferenciada resultante de la potestad financiera del Estado. La subvención no es un concepto que delimite competencias (Ss. TC 39/1982 y 179/1985) ni el solo hecho de financiar puede erigirse en núcleo que atraiga hacia sí toda competencia sobre los variados aspectos a que pueda dar lugar la actividad de financiación (Ss. TC 39/1982, 144/1985, 179/1985 y 146/1986), al no ser la facultad de gasto público en manos del Estado "título competencial autónomo" (Ss. TC 179/1985 y 145/1989) que "pueda desconocer, desplazar o limitar las competencias materiales que corresponden a las Comunidades Autónomas según la Constitución y los Estatutos de Autonomía» (S. TC 95/1986).

Que antes al contrario, "el ejercicio de competencias estatales anejas al gasto o a la subvención, sólo se justifica en los casos en que, por razón de la materia sobre la que opera dicho gasto o subvención, la Constitución o, en su caso, los Estatutos de Autonomía hayan reservado al Estado la titularidad de tales competencias sobre la materia subvencionada" (Ss. TC 95/1986 y 96/1990, fundamento jurídico 15). De modo que "la sola decisión de contribuir a la financiación no autoriza al Estado para invadir competencias ajenas -que lo siguen siendo a pesar de la financiación-, sino que, aun si estima que lo requiere el interés general, deberá desenvolver su actividad al amparo de una autorización constitucional y respetando en todo caso las competencias que la Constitución (que se entiende que también ha valorado el interés general) ha reservado a otros entes territoriales» (Ss. TC 146/1986 y 75/1989)».

En consecuencia, esto significa que la persecución del interés general que representa el Estado "se ha de materializar "a través de", no "a pesar" de los sistemas de reparto de competencias articulados en la Constitución" (S.TC 146/1986), excluyéndose así que el ámbito de competencias pueda ser extendido por meras consideraciones finalísticas (S. TC 75/1989).

nos, Madrid, 1991). O los artículos de M. MEDINA GUERRERO. "La incidencia del poder de gasto estatal en el ejercicio de las competencias autonómicas» $\left(R E D C \mathrm{n}^{\circ} 30,1990\right)$ y J. RECASSENS CALVO, «Los límites constitucionales de la actividad de fomento en sectores de competencia de las Comunidades Autónomas" (REALA $\left.{ }^{\circ} 245,1988\right)$.

${ }^{3} \mathrm{Cfr}$. fundamento jurídico $4^{\circ}$. 
JURISPRUDENCIA

Por tanto, la legitimidad constitucional del régimen normativo y de gestión de las subvenciones fijado por el Estado depende de las competencias genéricas o específicas que el Estado posea en la materia de que se trate, competencias que, necesariamente, serán concurrentes con la que ostente la Comunidad Autónoma a la que se transfiera la subvención (Ss. TC 201/1988, fundamento jurídico 2, y 188/1989, fundamento jurídico 3). Pues "si se admitiera una competencia general e indeterminada de fomento de las actividades productivas por parte del Estado se produciría, junto a la indicada alteración del sistema competencial, una distorsión permanente del sistema de ordinario de financiación autonómica" (S.TC 152/1988, fundamento jurídico 3).

b) Por lo que se refiere a la regulación de las ayudas ${ }^{4}$,

"De ello se deriva que "el Estado no puede condicionar las subvenciones o determinar su finalidad más allá de donde alcancen su competencias de planificación y coordinación, la cual resultará excedida, con la consiguiente invasión competencial, si la especificación del destino de las subvenciones se realiza en tal grado de concreción y detalle que, no siendo imprescindible para asegurar el objetivo de la planificación, se prive a la Comunidad Autónoma de todo margen para desarrollar, en el sector subvencionado, una politica propia, orientada a la satisfacción de sus intereses peculiares, dentro de las orientaciones de programación y coordinación que el Estado disponga para el sector como componente del sistema económico general" (Ss. TC 201/1988 y 96/1990, fundamento jurídico 15)».

c) En cuanto a la gestión de las subvenciones 5 , señala el TC que,

"En relación con la gestión de las subvenciones estatales -el problema más agudamente debatido por las Comunidades Autónomas en los

\footnotetext{
${ }^{4}$ En otros pronunciamientos el TC ha establecido el contenido "normal» de esta regulación estatal de las ayudas, dependiendo, lógicamente, del concreto alcance de la competencia que el Estado titule en cada caso, y que sería el siguiente:

- La definición misma de las actuaciones protegibles, es decir, el propio objeto de la ayuda. - La definición de las formas de protección establecidas para cada modalidad de ayuda (si avales, becas, primas, subsidio de intereses...).

- Los niveles de protección establecidos para cada modalidad de ayuda (porcentaje de inversión a realizar por el beneficiario e idem cubierto por la ayuda).

- La determinación de los posibles beneficiarios de las ayudas.

- Las condiciones y garantías exigibles para la concesión de las ayudas.

-Y la previsión presupuestaria del volumen de los fondos estatales que se aportan para las ayudas.
}

5 Y teniendo en cuenta el supuesto especial constituído por la gestión de los planes estatales de reestructuración o reconversión de sectores económicos, supuesto en el que la doc- 
numerosos conflictos competenciales planteados-el Tribunal se ha cuestionado "si tiene sentido y es eficaz un sistema de subvenciones centralizadas en un sector económico que ha sido descentralizado y atribuido a la competencia exclusiva de las Comunidades Autónomas" 6(Ss..TC 95/1986, fundamento jurídico 5 y 152/1988, fundamento jurídico 5). Concluyéndose, a este respecto, que la gestión por el Estado, directa y centralizada, de las medidas de fomento con cargo a fondos estatales, sólo es constitucionalmente admisible "si resulta imprescindible para asegurar la plena efectividad de las medidas de fomento dentro de la ordenación general del sector, y para garantizar las mismas posibilidades de obtención y disfrute de las mismas por parte de todos los destinatarios potenciales en todo el territorio nacional, siendo al mismo tiempo un medio necesario para evitar que se sobrepase la cuantía global de los fondos o de los créditos que hayan de destinarse al sector" (Ss. TC 96/1986, 152/1988 y 201/1988). En otro caso -esto es, si no concurre alguna de las citadas circunstancias - la regla general es la gestión autonómica o descentralizada de las subvenciones de acuerdo con la normativa estatal básica, debiendo transferirse a las Comunidades Autónomas los recursos estatales destinados a la financiación de las actividades que se fomentan bien sea mediante la fijación de criterios objetivos de reparto o mediante convenios ajustados a los principios constitucionales (Ss. TC 95/1986, 152/1988, 201/1988, 75/1989 y 188/1989)" 7.

\section{LA S.TC 13/1992, DE 13 DE FEBRERO}

\section{A) Potestad de gasto estatal y autonomía financiera autonómica}

La doctrina del TC expuesta en el epígrafe anterior respecto de la potestad de gasto público estatal es aplicable también, lógicamente, a

\footnotetext{
trina general del TC es la de considerar la gestión de los mismos como una tarea común del Estado y las CC.AA. competentes, por exigir esta gestión una confluencia de competencias estatales y autonómicas concurrentes para conseguir un objetivo común. Esta concurrencia competencial determina la existencia de una "responsabilidad común" y la necesidad de reconocer y prever canales de articulación de esa participación autonómica en los órganos gestores de esos programas. (Argumentos extraídos de las Ss. TC 29/1986 y 199/1989).

${ }^{6}$ En esa misma S.TC 95/1986, fundamento jurídico $5 .^{\circ}$, se añade que «las facultades de gestión en materias de competencia exclusiva de las Comunidades Autónomas les corresponde en principio a ellas". En esta misma línea, ver las Ss. TC 152/1988, 75/1989 y $145 / 1989$ entre otras.

7 Y teniendo en cuenta que el otro de los presupuestos señalados por el TC para esta gestión descentralizada, aparte del previo reparto de los fondos entre las CC.AA. competen-
} 
la correspondiente a las CC.AA. 8. En principio, podríamos concluir que no hay mayores diferencias en la consideración de ambas potestades de ejecución de los respectivos presupuestos, en la medida en que el carácter instrumental del poder financiero determinaría que cada ente territorial de los que integran el Estado compuesto sólo pudiese usarlo dentro del marco de sus competencias materiales.

Pero la jurisprudencia TC referente a la autonomía financiera de las CC.AA. ${ }^{9}$, insiste en la diferenciación entre ésta que podríamos denominar autonomía de gasto autonómica y la, en palabras del propio TC, «soberanía» de gasto del Estado, concebida ésta última en unos términos que acercarían al sistema español de relaciones financieras entre el Estado y las CC.AA. a los sistemas federales cooperativos, especialmente, desde nuestro punto de vista, al modelo cooperativo de los EUA ${ }^{10}$, como intentaremos justificar más adelante.

tes, es el de la observancia de los principios de colaboración, lealtad y cooperación, tal y como se recoge en las Ss. TC 106/1987 y 201/1988.

De este modo, en la primera de ellas se advierte que las dificultades de orden técnico que puedan existir para llevar a cabo esta gestión descentralizada, no pueden servir de excusa para negarles a las CC.AA. el ejercicio de esa su competencia. Por el contrario, obliga al establecimiento de instrumentos de colaboración entre las CC.AA. competentes y el Estado. En la segunda, se señala que en la conjunción de actividades estatales y autonómicas, necesaria para satisfacer el derecho a la vivienda proclamado en el art. $47 \mathrm{CE}$, se debe atender no sólo al respeto estricto de las competencias ajenas, sino también a los principios de colaboración y solidaridad y, en fin, a una exigible actitud de lealtad constitucional.

8 Recordemos que la primera sentencia en la que el Alto Tribunal establece esa doctrina, la S.TC 39/1982, se refería precisamente a la potestad de gasto de la Comunidad Autónoma del País Vasco.

${ }^{9}$ Autonomía financiera que en el caso español halla su más importante y casi única expresión en la vertiente del gasto, por cuanto las CC.AA. sujetas al sistema ordinario de financiación no cuentan con un sistema tributario propio con potencia recaudatoria bastante como para proveer a la cobertura financiera de sus competencias. Como reconoce el TC en la S. 13/1992, fdto. jco. $7 .^{\circ}$.

"Ante todo conviene recordar, como uno de los rasgos caracteristicos del sistema de financiación de las Comunidades Autónomas diseñado por la LOFCA, en el marco de la Constitución, que la autonomía financiera de las Comunidades Autónomas viene definida en el bloque de la constitucionalidad más por relación a la vertiente del gasto público - y si acaso a la de las transferencias de ingresos procedentes de la hacienda estatal y que constituyen un derecho de crédito frente a ésta a favor de las haciendas autonómicas (...) - que por relación a la existencia y desarrollo de un sistema tributario propio con virtualidad y potencia recaudatoria suficientes para cubrir las necesidades financieras de la hacienda autonómica. Se configura asi un sistema de financiación apoyado en mecanismos de transferencia financiera desde el Estado".

10 En este sentido, según algunos autorizados representantes gubernamentales autonómicos (y citamos aquí la intervención de D.J. BALZA. Viceconsejero de Régimen Jurídico 
De este modo, se insiste en que la autonomía financiera de las CC.AA., tal y como se concibe en la CE (art. 156) y en la LOFCA (art. $\left.1.1^{\circ}\right)$, se ciñe estrictamente al ámbito de sus competencias ${ }^{11}$, como se recoge, por sólo poner algunos ejemplos, en la S.TC 14/1989 12, en tanto que la potestad de gasto del Estado apodera a éste para dedicar sus fondos a cualquier finalidad lícita, lo que a nuestro juicio constituye una evidente contradicción con la doctrina constitucional expuesta en el epígrafe anterior. Así claramente se dice en la reciente S.TC 13/1992 que,

"Puede decirse, con razón, que el poder de gasto del Estado o de autorización presupuestaria, manifestación del ejercicio de la potestad legislativa atribuida a las Cortes Generales (art. 66.2. ${ }^{\circ}$ y 134 CE) no se define por conexión con el reparto competencial de materias que la Constitución establece (art. 148 y 149 CE), al contrario de lo que acontece con la autonomía financiera de las Comunidades Autónomas, que se vincula al desarrollo y ejecución de las competencias que, de acuerdo con la Constitución, le atribuyen los respectivos Estatutos y las Leyes (art. 156.1. ${ }^{\circ} \mathrm{CE}$ y art. 1.1. ${ }^{\circ}$ LOFCA). Por consiguiente el Estado siempre podrá, en uso de su soberanía financiera (de gasto, en este caso), asignar fondos públicos a unas finalidades $u$ otras, pues existen otros preceptos constitu-

y Desarrollo Autonómico del Gobierno vasco, en el Seminario coorganizado por la UPV y el IVAP dedicado a la reforma del Senado y las Comunidades Autónomas, Bilbo, 28 y 29 de mayo de 1992), la S.TC 13/1992 - donde más nítidamente se observa la diferente consideración señalada en el texto- establecería un modelo de relaciones financieras propio del federalismo cooperativo.

11 Destacar que las "competencias propias", aparte de un límite negativo a la autonomía financiera de las Comunidades Autónomas, constituye también una determinación positiva del alcance de aquélla. Esta determinación positiva implica, por ejemplo, la inconstitucionalidad de determinados controles estatales sobre la gestión autonómica de programas de subvención financiados con fondos estatales, calificados por el TC de exorbitantes; es decir, cuando,

"No se manifiesten imprescindibles para asegurar la coordinación de la política economica en un determinado sector con la programación a nivel nacional que haya realizado el Estado en uso de las competencias que a tal efecto le confiere la Constitución".

Este es el caso de que a través de una simple comunicación administrativa se deje en manos del Director General de Producción Agraria, la disposición o reserva de los créditos, supeditando su libramiento a la remisión previa por parte de las CC.AA. de una información normalizada en la que se contenga la relación de beneficiarios y el objeto y cuantía de las subvenciones aprobadas en el trimestre anterior. (Supuesto contemplado en la S.TC 201/1988, fdto. jco. $4^{\circ}$ ).

12 "la autonomía financiera, si bien garantiza a las Comunidades Autónomas la plena disposición de los medios financieros, no supone que esa potestad de gasto permita a las Co- 
JURISPRUDENCIA

cionales (y singularmente los del Capítulo III del Título I) que legitiman la capacidad del Estado para disponer de su Presupuesto en la acción social o económica»13.

De esta forma, y como se afirma en el párrafo siguiente del propio fundamento jurídico $7 .^{\circ}$ de la S.TC 13/1992,

«Es evidente que en el sistema español de distribución territorial del poder, el Estado puede asignar sus recursos a cualquier finalidad lícita y que la definición de esta finalidad en la Ley de Presupuestos condiciona necesariamente la libertad de acción de aquellas instancias que hayan de utilizar esos recursos» 14 .

munidades Autónomas financiar o subvencionar cualquier clase de actividades, sino solamente aquéllas en las que sean competentes, pues la potestàd de gasto no es un título competencial que permita alterar el orden competencial diseñado por la Constitución y los Estatutos de Autonomía» (Cfr., S.TC 14/1989, fdto. jco. 2. ${ }^{\circ}$ ).

13 Cfr., S.TC $13 / 1992$, fdto. jco. $7 .^{\circ}$. Esta soberanía de gasto estatal, no es más que la traducción al ámbito financiero de una concepción reiterada por el TC respecto del concepto de autonomía del art. $137 \mathrm{CE}$. Ya en la S.TC 1/1981 de 2 de febrero, decía el Alto Tribunal que

«...resulta claro que la autonomía hace referencia a un poder limitado. En efecto, la autonomía no es soberanía -y aun ésta tiene sus límites-..."

En la misma línea, la S.TC 25/1981, de 28 de julio de 1981 afirma que

«La autonomía reconocida, entre otros entes, a las Comunidades Autónomas por el art.

$137 \mathrm{CE}$, se configura como un poder limitado que no es soberanía. La autonomía se reconoce a los entes territoriales enumerados en aquel artículo para "la gestión de sus respectivos intereses", lo que exige que se dote a cada ente de todas las competencias propias y exclusivas que sean necesarias para satisfacer el interés respectivo".

14 Este reconocimiento al Estado del poder de, al amparo de su potestad de gasto, asignar fondos de sus presupuestos a cualquier finalidad lícita, nos hace recordar aquella jurisprudencia del TS de los EUA en la que, con base en el poder de gasto implícito en la cláusula de bienestar general del art. 1.8. ${ }^{\circ}$ de la Constitución ( $\mathrm{El}$ Congreso tendrá la facultad (...) para (...) proveer al bienestar general de los Estados Unidos»), se le reconoció al Congreso el poder de asignar fondos federales a cualquier fin lícito en cualquier parte del territorio y con independencia de si las materias sobre las que recayesen las "grants" federales fuesen propias de la competencia de los Estados federados. Una clara exposición del alcance y fundamento de este "spending power» lo hallamos en la sentencia del TS que resuelve el caso United States V. Butler, del año 1935. Siguiendo a A. MONREAL FERRER, La nación y los estados en el federalismo norteamericano. La interpretación judicial de las subvenciones federales. PPU, Barcelona, 1990, pág.72.

«En primer lugar, "el poder del Congreso de autorizar gastos de fondos públicos no está limitado por las directas atribuciones de poder legislativo que la Constitución le confie$r e "$ de manera que se entendia que podía atender a otras finalidades distintas de las comprendidas en la relación de competencias constitucionales del gobierno federal.

En segundo lugar, dicha interpretación concluía con la polémica en la doctrina sobre los limites del "spending power" que se remontaba a Madison y Hamilton, el primero 

entre dos polos aparentemente antitéticos como son, por una parte, la

vinculándolo al ejercicio de las competencias especificamente atribuidas y el segundo sosteniendo que la cláusula confería un poder "separado y distinto" de los enumerados, de modo que constituía por si mismo un poder "sustantivo"; la preferencia por Hamilton se justificaba en que la posición de Madison era una tautologia, en el sentido de que en el caso de ser la interpretación adecuada no hubiese habido ninguna necesidad de establecer la clausula como tal.

$Y$, en tercer lugar, que a pesar no estar de no estar vinculado al ejercicio de los poderes enumerados no por eso dejaba de estar sometido a límites».

Los paralelismos son evidentes: el poder de gasto se sustenta en ambos casos en una potestad genérica (cláusula de bienestar general para el caso de los EUA; principios rectores, art. $9.3 .^{\circ}$ y $149.1^{\circ} .1^{a} \mathrm{CE}$ para el caso español) que permite a las instancias centrales, en función de sus mayores disponibilidades presupuestarias, dedicar recursos a la subvención de actividades, incluso en materias propias de la competencia de los entes subcentrales. Las consecuencias de la afirmación de un poder financiero independiente del ámbito de las competencias materiales concretas lleva también a la negación -al menos en la práctica- de la existencia de competencias exclusivas de dichos entes.

Con todo, también hay diferencias: el fundamento básico del sistema de subvenciones federales en los EUA, aparte de la cláusula de bienestar general, es la aceptación por parte de los Estados de las condiciones anejas a las ayudas, aceptación que excluye de entrada la posibilidad de extralimitación competencial por parte de la federación. Como señala el TS de los EUA en la sentencia Massachusets V.Mellon 1923 - citada por A. MONREAL FERRER, op. cit., pág. 75.

«En última instancia la queja del Estado demandante sostiene que el Congreso usurpó los poderes reservados de varios Estados por la mera promulgación de la ley, a pesar de que nada se ha hecho y que nada va a hacerse sin su consentimiento; y es evidente que esta cuestión, tal y como es presentada, tiene caracter político y no judicial, y por lo tanto no es asunto que admita el ejercicio del poder judicial».

Por el contrario, un razonamiento semejante es expresamente rechazado por el TC español:

«Se podría pensar que mal puede el Estado lesionar la autonomía política y financiera de las Comunidades Autónomas, cuando éstas en modo alguno están obligadas a aceptar la subvención establecida en los Presupuestos Generales del Estado para acciones o servicios de la competencia exclusiva de aquéllas. De manera que la Comunidad Autónoma siempre podría evitar la lesión a su autonomía política o la invasión competencial rechazando la subvención en la forma prevista en los Presupuestos Generales del Estado y si en uso de su autonomía de la voluntad acepta, prestando su consentimiento a las condiciones y modo de la subvencion, ello priva de fundamento a toda queja competencial en este sentido, pues será como ir en contra de sus propios actos. Pero un razonamiento semejante seria constitucionalmente inaceptable porque la autonomía y las propias competencias son indispensables tanto para el Estado como para las Comunidades Autónomas y porque, como se dijo en la S.TC 201/1988, fundamento jurídico $4^{\circ}$, la autonomía financiera de las Comunidades Autónomas reconocida en los artículos $156.1 .^{\circ}$ de la Constitución y $1.1 .^{\circ}$ de la LOFCA exige la plena disposición de medios financieros para poder ejercer, sin condicionamientos indebidos y en toda su extensión, las competencias propias, en especial las que se configuran como exclusivas».(S.TC 13/1992, fundamento jurídico $7 .^{\circ}$ ). 
negación de una competencia subvencional en manos del Estado entendida como un poder libre y desvinculado del orden competencial ${ }^{15}$, y por otra, la afirmación de la capacidad que el Estado tiene -como manifestación de la función legislativa presupuestaria atribuída por la $\mathrm{CE}$ a las Cortes Generales 16_ de asignar fondos de sus presupuestos al logro de cualesquiera finalidades lícitas, puesto que aquel poder de las Cortes Generales no se define por conexión con el reparto competencial de materias que la CE establece en los art. 148 y 149 17. La solución tiene que partir, pues, de la afirmación de ese poder soberano del Estado, si bien respetando el orden competencial.

\section{Cfr. S.TC $13 / 1992$, fdto. jco. $6^{\circ}$.}

16 Que en su configuración actual -como Cámaras de representación general y no territorial, y a la espera, en todo caso, de una eventual reforma del Senado- no son sino parte del aparato central del Estado, es decir, de uno solo de los sujetos integrantes del compositum que es el Estado de las autonomías.

17 Cfr. S.TC $13 / 1992$, fdto. jco. $72^{\circ}$. Advertir que esa afirmación de desvinculación del orden competencial no es exacta: si lo fuese, la contradicción con la doctrina TC referida a la potestad de gasto tanto del Estado como de las CC.AA., sería insalvable. De este modo -éste sería, a nuestro juicio, el iter del razonamiento del Alto Tribunal-es necesario encontrar un, aunque sea débil, apoyo competencial. Sabido que éste no se halla en los arts. 148 y $149 \mathrm{CE}$ se acude a una imprecisa legitimación del Estado para intervenir en la política social y económica -locución empleada por el Acuerdo 1/1986 que aprueba el sistema de financiación de las CC.AA. para el período 1987-1991 y repetida en la S.TC 13/1992 - que no se fundamenta en los preceptos del Título VIII, sino en los derechos sociales, principios rectores de la política social y económica del Título I, Capítulo III CE. Solución que, desde nuestro punto de vista, desde una interpretación sistemática de la CE no es correcta: el llamamiento que en los arts. 39 a 52 de la CE se contiene a los "poderes públicos" no implica que todos ellos puedan intervenir simultánea o indistintamente en la realización de los objetivos a los que estos preceptos los emplazan, lo que chocaría frontalmente con principios constitucionales como el de eficacia. La competencia será de aquel ente al que le corresponda conforme al reparto competencial por materias que configura el bloque de la constitucionalidad (Título VIII CE y Estatutos de Autonomía) y será también éste, por tanto, el legitimado para —en la medida del alcance de sus competencias- elaborar y ejecutar una política propia orientada a la satisfacción de aquellos objetivos, correspondiéndole en todo caso al Estado una función de garantía en virtud del art. $149.1 .^{\circ} \cdot 1^{\mathrm{a}} \mathrm{CE}$.

Por el contrario, el TC sigue entendiendo que

"Las subvenciones estatales pueden tender a asegurar las condiciones básicas de igualdad cuya regulación reserva al Estado el artículo $149.11^{\circ} .1^{\circ} \mathrm{CE}$, poniéndose de este modo el spending power estatal servicio de una política de equilibrio social en sectores que lo necesiten, en ejecución de mandatos o cláusulas constitucionales genéricas (art. 1.1. ${ }^{\circ}$ $o$ art. 9.2. ${ }^{\circ} \mathrm{CE}$ ) que, aunque obligan a todos los Poderes Públicos, corresponde prioritariamente realizar a quien mayor capacidad de gasto tiene». (Cfr. S.TC 13/1992, fdto. jco. $\left.7 .^{\circ}\right)$. 
La cuadratura del círculo se alcanza a través de una sutil distinción entre la asignación de los fondos presupuestarios, es decir, el establecimiento de las subvenciones ${ }^{18}$, que sí operaría al margen del reparto competencial fijado por el Título VIII CE, y la programación y ejecución de ese gasto, en la que el Estado sí tiene que respetar el orden competencial, bajo el riesgo de vaciar de contenido la autonomía política y financiera de las CC.AA. De esta forma, el modelo de relaciones financieras propuesto por el TC en la S. 13/1992 sería el siguiente:

-En el supuesto de que la materia a la que se refieren las asignaciones presupuestarias sea de competencia exclusiva del Estado, no se plantea, lógicamente, ningún problema de delimitación competencial entre el estado y las CC.AA.: será a las instancias competentes a las que corresponda en toda su extensión la programación y ejecución del gasto.

- Caso de encontrarnos ante materias de competencia, en mayor o menor grado, de las CC.AA. ${ }^{19}$,

"...las medidas que hayan de adoptarse para conseguir la finalidad a que se destinan los recursos deberán respetar el orden constitucional y estatutario de las competencias, sin imponer a la autonomía politica de las Comunidades Autónomas otros condicionamientos que aquéllos que resultan de la definición del fin o uso que el Estado puede hacer de otras competencias propias, genéricas o específicas.

De otro modo, si así no fuera y se admitiese que el asignar sus propios recursos a objetivos específicos en sectores o ámbitos de competencia exclusiva de las Comunidades Autónomas, el Estado pudiera regular el modo, las condiciones y la manera en que han de emplearse por las Comunidades Autónomas los fondos estatales transferidos, entonces el Estado estaría restringiendo la autonomía política de las Comunidades Autónomas y su capacidad de autogobierno que se manifiesta, sobre todo, en la capacidad para elaborar sus propias políticas públicas en las materias de su competencia, forzándolas a una suerte de regateo o negociación con el Estado so pena de perder los fondos asignados a la subvención».

Es decir, más concretamente, la afectación de los fondos presupuestarios a finalidades determinadas de política económica o social -que corresponde, como ya vimos, al Estado- para ser respetuosa con el orden competencial, tiene que ser...

\footnotetext{
18 Esta asignación de fondos públicos a unas u otras finalidades sería la "...constatación del señorio del Estado sobre su presupuesto, esencia misma del poder financiero (la capacidad de decisión sobre el empleo de sus propios recursos» (S.TC 13/1992, fdto, jco. 7. ${ }^{\circ}$ ).

${ }^{19}$ Cfr. de nuevo, S.TC 13/1992, fdto. jco. $7 .^{\circ}$.
} 
JURISPRUDENCLA

«... global o genérica, en función de materias o sectores de la actividad económica o social, de manera que la especificación presupuestaria de los créditos sea la mínima imprescindible para acomodarse a las exigencias del principio de la legalidad presupuestaria y deje el margen necesario de actuación para que las Comunidades Autónomas puedan ejercer su competencia exclusiva en la materia (...). Siendo evidente que el Estado no puede condicionar las subvenciones o determinar su finalidad más allá del alcance de los títulos en que ampare su intervención.

En aquellas materias en que el Estado ostente algún título competencial y en la medida de su competencia podrá ejercitarlas mediante acciones de fomento o subvenciones, fijando normativamente las condiciones de su empleo por las Comunidades Autónomas (y ello respetando en todo caso las competencias ejecutivas o de gestión que puedan corresponder a éstas según el orden de reparto competencial en la materia) y, en su caso, disponer la gestión directa y centralizada de los fondos presupuestarios si resultara imprescindible...

Ello no significa, claro está, desapoderar al Estado para toda intervención en aquellas materias en que los Estatutos de Autonomía atribuyen a las Comunidades Autónomas competencias exclusivas, pues el Estado puede ostentar competencias concurrentes por virtud de títulos reconocidos en el art. 149 CE y en los Estatutos de Autonomía para desarrollar o establecer políticas económicas o sociales de ordenación sectorial o de servicios o su actuación se enmarque en las facultades estatales de dirección y coordinación de la política económica, en cuanto las subvenciones deque en cada caso se trate puedan constituir un elemento esencial de la misma (...)».

En fin, concluye el TC este fundamento jurídico $7 .^{\circ}$ de la S.TC 13/1992, recordando la necesidad de los instrumentos y técnicas de cooperación y colaboración -especialmente de los convenios de colaboración ajustados al orden constitucional de competencias-, como las más adecuadas para la articulación de esos supuestos de concurrencia competencial entre el Estado y las CC.AA. ${ }^{20}$, para, ya en el fundamento jurídico $8 .^{\circ}$, analizar uno a uno los posibles supuestos de concurrencia competencial Estado-CC.AA. en el ámbito del fomento:

a) El primero de los supuestos sería aquél en el que una Comunidad Autónoma ostenta una competencia exclusiva sin que el Estado invoque ningún título competencial (genérico o específico) sobre la misma.

\footnotetext{
20 "Técnicas consustanciales a nuestro modelo de Estado autonómico que deberían ser acordadas en este y otros sectores entre los órganos centrales del Estado y las Comunidades Autónomas, buscando entre todos, dentro del respectivo e indispensable marco competencial, métodos flexibles y adecuados de convergencia que disminuyan la conflictividad entre aquellos poderes, todos los cuales deben guiarse siempre por una común lealtad constitucional».
} 
En este caso, el Estado puede decidir asignar sus fondos presupuestarios a esas materias, pero,

"...de una parte, la determinación del destino de las partidas presupuestarias correspondientes no puede hacerse sino de manera genérica o global, por sectores o subsectores enteros de actividad. Por otra parte, esos fondos han de integrarse como un recurso que nutre la Hacienda autonómica. consignándose en los Presupuestos Generales del Estado como transferencias corrientes o de capital a las Comunidades Autónomas, de manera que la asignación de los fondos quede territorializada, a ser posible, en los mismos Presupuestos Generales del Estado".

b) El segundo caso se produciría cuando el Estado ostente un título genérico de intervención (v.gr., el de ordenación general de la economía) superpuesto a una competencia autonómica incluso exclusiva, o bien tenga la competencia sobre las bases o de coordinación general de un sector o materia, con el correlato de la correspondiente competencia autonómica de desarrollo normativo y ejecución. En este caso, el Estado, aparte de consignar subvenciones de fomento en sus propios presupuestos ${ }^{21}$, puede especificar su destino y regular sus condiciones esenciales de otorgamiento en la medida en que lo permita su competencia genérica, básica o de coordinación. En todo caso hay que dejar siempre un margen a las CC.AA. para concretar la afectación o destino con más detalle o, al menos, para desarrollar y complementar la regu-

21 Notar la diferenciación que en la propia S.TC 13/1992, fdto. jco. $6^{\circ}$, establece el Tribunal entre subvenciones-dotación y subvenciones de fomento. Las subvenciones-dotación, más que subvenciones en sentido propio serían

«...meras dotaciones presupuestarias destinadas a cubrir las necesidades de financiación de un determinado ente o servicio público (...) constituyendo en realidad transferencias presupuestarias para asegurar la suficiencia financiera del ente público receptor (...) o, sencillamente, una forma de financiación del mismo".

La competencia del Estado para establecerlas se residenciaría en el título de Hacienda General del art. 149.1. ${ }^{\circ} 14 \mathrm{CE}$, cuando esa medida coyuntural se refiera a la relación de la Hacienda estatal con las Haciendas locales. Pero en el caso de subvenciones-dotación para servicios transferidos a las CC.AA. y que no formen parte del coste ordinario de éstos, estas subvenciones.

"...corresponden como un recurso propio a las Comunidades Autónomas debiendo transferirse globalmente por el Estado para ser integrados en los Presupuestos de la $\mathrm{Ha}$ cienda autonómica sin otro condicionamiento que el genérico estrictamente indispensable para asegurar el destino de la subvención afectándolo a la finalidad prevista en los Presupuestos Generales del Estado, de modo que se respete la autonomía financiera de las Comunidades Autónomas». (Este sería el caso de las subvenciones estatales en materia de competencia exclusiva de las CC.AA. sin ninguna concurrencia competencial con el Estado, contemplado en el apartado «an del texto).

Por su parte, en la terminología del TC, subvenciones de fomento serían aquéllas que se contemplan ya en los presupuestos como subvenciones a terceros. 
lación de las condiciones de otorgamiento y de tramitación de las ayudas. Asimismo, la gestión de las ayudas corresponderá como regla general a las CC.AA., de manera que tampoco se puedan consignar los fondos a favor de un órgano de la Administración del Estado, por tratarse de partidas que deben territorializarse, bien en los propios presupuestos, bien en un momento inmediatamente posterior, a través de normas que fijen criterios objetivos de reparto, bien a través de convenios de colaboración ajustados a los principios constitucionales.

c) Un tercer supuesto se daría cuando el Estado tuviese atribuída la competencia de legislación relativa a una materia, ostentando sólo las CC.AA., competencias de ejecución de esa normativa estatal. Según el TC, la única diferencia respecto del caso anterior es la de que en éste...

"...el Estado puede extenderse en la regulación de detalle respecto del destino, condiciones y tramitación de las subvenciones, dejando a salvo la potestad autonómica de autoorganización de los servicios».

d) El cuarto supuesto haría referencia a los supuestos excepcionales de gestión centralizada de las ayudas y subvenciones por órganos estatales, incluso en el caso de que las CC.AA. ostenten una competencia exclusiva en el sector o materia al que estas ayudas se refieran. Con todo, subraya el Tribunal que esto sólo puede ser posible cuando, además de titular el Estado una competencia genérica o específica en la materia, concurra alguna de las ya conocidas circunstancias: que resulte imprescindible para asegurar la plena efectividad de las medidas dentro de la ordenación básica del sector, para garantizar las mismas posibilidades de obtención y disfrute a sus potenciales destinatarios en todo el territorio del Estado y para evitar que se sobrepase la cuantía global de los fondos estatales destinados al sector.

\section{B) La territorialización de las partidas presupuestarias que pre- vean subvenciones estatales en materias de competencia de las CC.AA.}

Al tiempo que el TC se cuestionaba la precisión $-\mathrm{y}$ también la constitucionalidad- de un sistema de gestión de ayudas centralizado en sectores que habían sido descentralizados y atribuidos a la competencia exclusiva de las CC.AA., apuntaba como el más respetuoso con el diseño constitucional, un sistema de gestión descentralizada en que los fondos correspondientes fuesen atribuídos a las CC.AA. bien a través de criterios objetivos de reparto, bien a través de convenios ajustados a los principios constitucionales, es decir, que el propio TC considera la territorialización de los fondos presupuestarios estatales asignados al fomento en materias 
de competencia de las CC.AA., como presupuesto imprescindible de la gestión autonómica de las ayudas que, como ya vimos, es la regla general a salvo de excepcionales reservas de ejecución a favor del Estado.

En todo caso no fue hasta la S.TC 13/1992, cuando el tema de la territorialización alcanzó - conectado con el de la autonomía financiera de las CC.AA. - un papel central en la jurisprudencia constitucional referente a las relaciones financieras entre el Estado y las CC.AA. De este modo, en la propia fundamentación de los recursos, el representante de la Generalitat de Catalunya calificó a esta territorialización de determinadas partidas presupuestarias entre las CC.AA. competentes, como una manifestación específica de la autonomía financiera de las CC.AA. exigida por la propia jurisprudencia constitucional, territorialización que deviene más necesaria para una efectiva tutela de la autonomía financiera de las CC.AA. si entendemos - de acuerdo con la fundamentación del recurso- que el sistema "definitivo " de financiación de las CC.AA. para el período 1987-1991, aprobado por el Acuerdo 1/1986 de 7 de noviembre del CPFF, reduce el llamado bloque de financiación incondicionada en tanto que incluye en el de financiación condicionada «todos aquellos recursos a través de los que se realizan los objetivos generales de política económica y social del Estado, cuya gestión y ejecución corresponda a las Comunidades Autónomas». Entiende la recurrente que la asignación centralizada de los fondos de estas partidas a órganos estatales $-\mathrm{y}$, por lo tanto, su no territorialización conforme a criterios objetivos en la propia Ley de Presupuestos- supone una reducción y condicionamiento ilegítimo de la autonomía financiera y política autonómica, ya que los fondos,

«... pueden no llegar, o llegar sólo en parte, o llegar condicionados a través de convenios con el Estado».

En cuanto a la gestión de estas subvenciones, su asignación centralizada a órganos estatales no permite una verdadera ejecución autonómica conforme con las competencias asumidas, al predeterminar ya que la gestión de los recursos corresponde a aquellos órganos estatales, de manera tal que la posible gestión autonómica se realizaría bajo el control directo de los mismos, situación sólo justificable en el caso de que no ostenten las CC.AA. ninguna competencia en la materia.

Como conclusión, la Generalitat propone unos requisitos mínimos que han de cumplir las subvenciones estatales previstas en las Leyes de Presupuestos para respetar, tanto la autonomía financiera como las competencias asumidas por las CC.AA., y que serían:

- Para las partidas presupuestarias destinadas al fomento en materias de competencia de las CC.AA., su territorialización directamente 
JURISPRUDENCIA

en la propia Ley de Presupuestos o, si hubiese dificultades de carácter técnico, en un momento posterior, pero siempre consignándose como créditos presupuestarios en los conceptos de transferencias - corrientes o de capital- del Estado a las CC.AA., y nunca directamente asignados a órganos estatales.

- Cuando se trate de materias en las que, al menos, titulen las CC.AA. una competencia de ejecución, la fórmula no puede ser la de la gestión centralizada por órganos estatales, sino la vía de la cooperación si bien, se advierte, no desnaturalizada a través de convenios obligatorios.

-Finalmente, se pide que el reparto de los fondos se realice por medio de la aplicación de criterios objetivos de reparto y no a través de convenios obligatorios.

Por su parte, el Abogado del Estado inicia la contestación al recurso con un entendimiento que ciertamente no se compadece, a nuestro juicio, con el modelo de relaciones financieras que la CE traza 22 , estableciendo un concepto muy estricto de la autonomía financiera autonómica, al decir que

«En nada afecta a la autonomía de gasto comunitaria la posibilidad de que el Estado disponga de sus propios fondos, salvo interferencias o contradicciones concretas que en el recurso no se denuncian" 23.

22 Aparte del hecho constatado por el TC de que las normas que componen el bloque de la constitucionalidad sólo realizan una imprecisa e insuficiente articulación de las relaciones financieras entre la Administración central y las Administraciones autonómicas (Cfr. S.TC 13/1992, fdto. jco. $2^{\circ}$ ), la CE - y especialmente la LOFCA - contienen elementos suficientes para configurar un modelo de relaciones no de separación, sino de coordinación entre las Haciendas autonómicas - y locales-y la estatal, como bien se puede concluir del examen del art. $156.1 .^{\circ} \mathrm{CE}$.

${ }^{23}$ Argumento que esconde también la doctrina de la neutralidad competencial del presupuesto, recogida básicamente en las Ss. TC 63/1986 y 146/1986. De acuerdo con esta doctrina las Leyes de Presupuestos, al no ser las fuentes de las obligaciones económicas del Estado, no regulan ni predeterminan la forma en que el gasto haya de ser invertido, sino que simplemente autorizan la disposición de los fondos y predeterminan el concepto por el que autorizan su uso. De este modo, las partidas presupuestarias no tienen más función que la de "mera dotación económica para la actuación estatal en la materia", sin predeterminar ni crear, sino simplemente aplicando, las competencias que al Estado le hayan sido atribuídas y en la medida en que lo hayan sido, por las normas atributivas de competencias - CE y Estatutos- que son las verdaderamente habilitantes.

Con todo, y siendo ésta la doctrina general, también es sólo aplicable al supuesto más general de impugnación autonómica de partidas presupuestarias, cuando los criterios de distribución de las mismas se contengan en un acto distinto y externo a las Leyes de Presupuestos, o cuando tomando por base esa previsión presupuestaria haya el Estado lleva- 
Así, y partiendo de las «importantes matizaciones -incluso en el caso de competencias aparentemente exclusivas de las Comunidades Autónomas» introducidas por la S.TC 146/1986 respecto de la doctrina «tradicional" del TC referida a la potestad estatal de gasto público, entiende el representante estatal que los conceptos de incompetencia estatal y territorialización de los fondos son "contradictorios", porque es necesario un análisis concreto no de las partidas presupuestarias, sino de la disciplina normativa de las subvenciones o fondos concretos, para determinar si la gestión centralizada, o bien, la territorialización - en sus diferentes grados- previstas por la misma son o no conformes con el orden competencial, disciplina normativa que no se contiene en la Ley de Presupuestos. En conclusión,

"No cabe analizar en abstracto la adecuación de las partidas presupuestarias al orden competencial por el solo hecho de no preverse su territorialización que, por otra parte siempre será posible de acuerdo con lo dispuesto en el art. 123 de la referida Ley de Presupuestos Generales impugnada» 24.

Para el TC es claro que, para ser respetuosa con la autonomía política y financiera de las CC.AA., la acción de fomento del Estado en materias de competencia de la CC.AA., tiene que materializarse a través de:

do a cabo una regulación del régimen jurídico de las ayudas sin respetar las competencias autonómicas o bien, en el caso de que el Estado en la ejecución de las partidas, no respetase las competencias de ejecución de las CC.AA. Y, por eso, el TC añade —en la S.TC 13/1992, fdto. jco. 5. - que,

«...esa doctrina no puede ser aplicada de manera mecánica para negar la posibilidad (ya apuntada explícitamente en las Ss. TC 15/1986, fundamento jurídico $5 .^{\circ}$ y 88/1987, fundamento jurídico $\left.2 .^{\circ}\right)$ de que las Comunidades Autónomas impugnen las partidas del estado de gastos de las Leyes de Presupuestos Generales del Estado cuando lo que se cuestiona -como ahora acontece y era también el caso del conflicto de competencia resuelto en la S.TC 146/1986- es la competencia misma del Estado para, mediante el ejercicio de su poder financiero, centralizar en organismos de la Administración estatal los fondos destinados a subvenciones o ayudas en materia de competencia exclusiva de las Comunidades Autónomas.

Nada ha de oponerse, pues, en principio, a que las Comunidades Autónomas impugnen las Leyes de Presupuestos Generales del Estado, en cuanto expresión característica del poder de gastos (spending power) del Estado, autorizando créditos para subvenciones sobre materias o sectores económicos en los que pueda verse afectado el orden constitucional de distribución de competencias o la misma autonomía política y financiera de las Comunidades Autónomas".

24 Se refiere a la Ley de Presupuestos Generales del Estado para 1988, objeto del primero de los recursos de inconstitucionalidad acumulados y resueltos por la S.TC 13/1992. En todo caso, señalar que la fundamentación de la actora y la contestación del Abogado del Estado, coinciden sustancialmente en ambos casos. 
«...transferencias financieras para subvenciones (...) que (...) deben atribuirse directa e incondicionadamente a las Comunidades Autónomas nutriendo, como un recurso financiero más, la Hacienda autonómica. Técnica ésta de reparto territorial de las subvenciones para su gestión descentralizada por las Comunidades Autónomas que, como ya se dijo en la S.TC 95/1986, fundamento jurídico $5 .^{\circ}$, resulta la más ajustada al modelo de Estado de las Autonomías diseñado por la Constitución. Y a tal efecto, las dotaciones presupuestarias destinadas al fomento deben distribuirse de manera global y descentralizada entre las distintas Comunidades Autónomas según "criterios objetivos de reparto o bien mediante convenios ajustados a los principios constitucionales" (S.TC 152/1988, fundamento jurídico $\left.5 .^{\circ}\right) 25$.

En todo caso, debemos advertir que estos «buenos deseos» del TC resultan muy desleídos en lo que a su realización práctica se refiere, tanto por los términos en que se declara la inconstitucionalidad de determinadas partidas y preceptos de las Leyes de Presupuestos para 1988 y 198926 -habrá que aguardar para ver que sucede con la Ley de Presupuestos Generales para el año que viene, 1993-, cuanto por la solución concreta que el TC da a las impugnaciones particulares de las diferentes partidas encontrando, en la mayoría de los casos, competencias que permiten a la intervención estatal ir más allá de la simple especificación presupuestaria de los créditos, por ejemplo en materia sanitaria o incluso de asistencia social 27 , en los fundamentos 12 y siguientes de la S.TC 13/1992.

25 Cfr., S.TC 13/1992, fdto. jco. $7^{\circ}$.

26 Ver el fundamento jurídico 17 de esta S.TC 13/1992. Como señala al final.

"Por todo ello, el alcance de los efectos generales de la declaración de inconstitucionalidad acordada se limita a los futuros ejercicios presupuestarios posteriores a la fecha de publicación de esta sentencia en el "Boletín Oficial del Estado".

de manera que la declaración de inconstitucionalidad no supone la anulación de dichos preceptos y partidas presupuestarias, pertenecientes a ejercicios económicos ya cerrados, ni, por supuesto, la de las subvenciones ya concedidas a su amparo.

27 Así, en materia de asistencia social y ante la impugnación por la Generalitat de Cataluña de los arts. 55 y 45 de las Leyes de Presupuestos para 1988 y 1989 respectivamente, preceptos que, con idéntico contenido normativo, establecían una cuantía máxima para las pensiones asistenciales así como el límite de edad de los beneficios, pudo decir el TC -Cfr. S.TC 13/1992, fdto. jco. 14. ${ }^{\circ}$ - que

"...la inexistencia de un título competencial basado en el "poder de gastar", no impide al Estado el ejercicio de toda acción social y económica mediante la vía subvencional canalizando sus recursos financieros al fomento de programas generales o de actuaciones singulares, para lo que puede estar legitimado constitucionalmente por virtud de otros 


\section{C) Los instrumentos de la territorialización: los convenios entre el Estado y las Comunidades Autónomas}

Pese a la insistencia del TC español en declarar que su función no es la de proveer al legislador de un sistema de relaciones financieras entre el Estado y las CC.AA., sino simplemente la de determinar si los propuestos por éste se ajustan o no al marco constitucional 28 , lo cierto es que no dejó el Tribunal de afirmar la conveniencia constitucional de un sistema de asignación territorial de los fondos presupuestados previstos por el Estado para el fomento en materias de competencias de las CC.AA., asignación territorial que se realizaría a través, bien de criterios objetivos de reparto, bien de convenios entre el Estado y las CC.AA. ajustados a los principios constitucionales.

Aparte, es preciso tener en cuenta también la previsión del art. 153 del actual TR de la Ley General Presupuestaria, que al referirse a las subvenciones estatales gestionadas por las CC.AA. contempla una de las posibles vías —en palabras del propio TC 29 - para la territorialización de los fondos correspondientes a las subvenciones estatales que hayan de ser gestionadas por las CC.AA. ${ }^{30} \mathrm{El}$ supuesto del que este pre-

títulos competenciales en razón a la que el Estado -junto a los demás poderes públicos-viene compelido por el art. 9.2.) CE de promoción de la igualdad sustancial del individuo y de los grupos en que se integra...",

intentando esquivar con esta alambicada labor de interpretación constitucional, la realidad de la falta de un título competencial específico en la materia. (Sobre esta peculiar interpretación del llamamiento a los poderes públicos de los arts. 39 y ss. CE, reiterar la crítica vertida en este mismo trabajo).

$28 \mathrm{Cfr}$. fdtos. jcos. 11 in fine y 2 in fine también, de la S.TC 13/1992, especialmente éste en el que el Tribunal recuerda que,

"...ni el recurso de inconstitucionalidad, en ausencia de preceptos constitucionales que asi lo exijan, es la vía adecuada para obtener el establecimiento de uno u otro sistema de financiación de las Haciendas territoriales, o la coordinación de la actividad financiera de los distintos entes territoriales entre sí (S.TC 179/1985), ni nos incumbe a nosotros determinar "cuál es el más adecuado sistema de articulación de competencias estatales y autonómicas"; decisión esta que, "dentro de la Constitución, corresponde adoptar a los propios Poderes Públicos responsables de ello, tanto del Estado, como de las Comunidades Autónomas". (S.TC 145/1989, fundamento jurídico $6 .^{\circ}$ ), siendo la única función de este Tribunal la de decidir si las concretas disposiciones impugnadas invaden o no el marco de lo constitucionalmente admisible».

${ }^{29}$ Cfr. S.TC 13/1992, fdto. jco. $9^{\circ}$ in fine.

30 En resumen el sistema establecido por esta norma sería el siguiente:

-El instrumento técnico para la distribución de los fondos serían, en principio, unos criterios objetivos fijados por los Departamentos Ministeriales respectivos, oidas las CC.AA., y aprobados por el Gobierno. 
JURISPRUDENCIA

cepto parte es el de la asignación centralizada de los fondos a órganos estatales, es decir, un supuesto bien alejado del sistema que el propio TC declara como el "preferible» y que es el de que ya en los propios Presupuestos estatales, esos fondos aparezcan como transferencias corrientes o de capital a favor de las CC.AA. ${ }^{31}$ Y por más que después añada el propio Tribunal que,

"...la preferencia por esta opción no implica que se incurra en inconstitucionalidad cada vez que no se cumpla, pues puede ocurrir (...) que en determinados casos no sea posible introducir esa técnica en la Ley de Presupuestos, o que, aun siendo posible, concurran en su contra, a juicio del legislador estatal, otras razones",

lo que en todo caso sí resulta inadmisible desde un punto de vista constitucional es la

«...consignación centralizada de los fondos que deben gestionar las Comunidades Autónomas a favor de un Organismo dependiente de la propia Administración del Estado cuyos servicios ya han sido transferidos a las Comunidades Autónomas, salvo que por las razones o circunstancias ya señaladas por la doctrina de este Tribunal expuesta anteriormente, dicha centralización resulte justificada».

De manera que, siendo la del art. 153 LGP una de las posibles vías de asignación territorial de los fondos estatales, lo cierto es que, desde nuestro punto de vista, va a tener un difícil encaje dentro de estas nuevas técnicas de presupuestación ajustadas al Estado de las Autonomías adelantadas por la S.C 13/1992.

En cuanto al reparto de los fondos, ya en los propios presupuestos o bien, cuando esto no sea posible, en un momento posterior, entre las CC.AA. y a través de criterios objetivos, lo cierto es que ésta es una previsión siempre repetida en la doctrina constitucional desde la S.TC 95/1986 pero nunca desarrollada por ésta. En todo caso, no parece que la vía más adecuada para la fijación de estos criterios sea la recogida en el art. 153 LGP - fijación por el Gobierno del Estado tras oír a las

- La distribución territorial de los fondos tendrá que realizarse en todo caso antes del 15 de marzo de cada ejercicio.

- Los fondos se librarán a favor de las CC.AA. por cuartas partes y dentro de la primera quincena natural de cada trimestre. Cuando se trate de prestaciones de carácter personal o social, se harán efectivas por doceavas partes al comienzo de cada mes.

31 Cfr. S.TC 13/1992, fdto. jco. 9.. 
CC.AA. - si es que queremos de verdad garantizar la autonomía financiera de las CC.AA. En este punto 32 se echa en falta la inexistencia en el Estado español de una verdadera Cámara de representación territorial, con competencias también verdaderamente territoriales; la aprobación por un órgano de esta naturaleza de las Leyes de Presupuestos garantizaría en este punto el acierto $\multimap$ al menos, la legitimidad- de la fijación de los criterios de reparto de los fondos estatales entre las CC.AA.

Por lo que se refiere a los convenios de colaboración entre el Estado y las CC.AA., comenzar reiterando la doctrina constitucional sobre la colaboración y la cooperación, de la que podemos retener la esencial voluntariedad que estas técnicas de relación encierran, lo que supone denunciar como inconstitucionales aquellos convenios obligatorios a los que la Generalitat se refiere en la fundamentación del recurso, tal y como hace, por otra parte el propio TC ${ }^{33}$. De este modo, el ámbito pro-

32 Y en esto coincide la mayoría de la doctrina constitucionalista - a la luz de lo expuesto en el Seminario sobre la reforma del Senado y las CC.AA. ya citado- y es una competencia inexcusable de toda Cámara de representación territorial merecedora de tal nombre, de acuerdo con las experiencias del federalismo europeo - alemán y austríaco, básicamente- la de la aprobación por las mismas de las leyes que incidan en el régimen de los entes subestatales a los que representan (las llamadas en la doctrina federalista alemana "leyes federativas») entre las que, lógicamente, la Ley de Presupuestos ocupa un lugar muy importante.

33 "Tiene razón la Generalitat de Cataluña al rechazar que el Estado pueda interferir el ejercicio de las competencias autonómicas mediante convenios-programa o condicionados, si se trata de competencias plenamente exclusivas de las Comunidades Autónomas. La fórmula del Convenio no es, sin embargo, descartable en estos casos, puesto que responde a ese principio de cooperación inherente al Estado de las Autonomías y en el que debería profundizarse. Pero es obvio que no puede servir para que el Estado recupere competencias en sectores de actividad descentralizados por completo,pues como ya se dijo en la S.TC 96/1986, fundamento jurídico 3.", "es evidente que, con base en este deber de recíproco apoyo y mutua lealtad (que es el deber general de cooperación al que están sometidos el Estado y las Comunidades Autónomas), no pueden resultar ampliadas las competencias del Estado, ni es posible por lo mismo limitar o condicionar el ejercicio de las competencias autonómicas (...) a la celebración o cumplimiento de Convenio alguno entre las dos administraciones territoriales". Ni tampoco es admisible, como se dijo en la S.TC 95/1986, fundamento juridico $5^{\circ}$, que merced a dicho Convenio, la Comunidad Autónoma "haya podido renunciar a unas competencias que son indisponibles por imperativo constitucional y estatutario". En estos supuestos, el Convenio sólo puede servir para facilitar la puesta a disposición de las Comunidades Autónomas de los fondos destinados a subvenciones, si en los Presupuestos Generales del Estado se determina genéricamente su destino. Pero no podría ni siquiera condicionarse esa transferencia de fondos a la firma de un Convenio, pues, en todo caso, el Estado tiene la obligación de distribuir las subvenciones entre las Comunidades Autónomas "durante el ejercicio presupuestario, con la mayor antelación posible", según se ha dicho". (Cfr. S.TC 13/1992, fdto. jco. $10{ }^{\circ}$. 
JURISPRUDENCLA

pio de los convenios-programa en el ámbito del reparto de los fondos estatales entre las CC.AA. competentes es el supuesto de concurrencia competencial. En estos casos, el Estado puede

«...establecer sus condiciones, hasta donde alcance su competencia material, en vez de por una norma de obligado cumplimiento, mediante un Convenio-Programa, supeditando la transferencia de los fondos a las Comunidades Autónomas a la firma del Convenio correspondiente» 34.

\section{LA GESTIÓN AUTONÓMICA DE LAS AYUDAS COMUNITA- RIAS: LA S.TC 79/1992, DE 28 DE MAYO}

La S.TC 79/1992, es la primera -que nosotros sepamos- en la que el TC español aborda directamente la cuestión de la gestión por las CC.AA. de las ayudas procedentes de los fondos estructurales de la Comunidad Europea sin introducir diferencias sustanciales respecto de la doctrina establecida con relación a la ejecución autonómica de las ayudas establecidas por el Estado, como no podía ser de otra forma atendiendo a la plena autonomía que, por lo general, reconoce el Derecho comunitario a los Estados miembros para designar, conforme a sus propias reglas de derecho interno, los órganos llamados a su aplicación.

La sentencia resuelve varios conflictos de competencia promovidos por los Gobiernos vasco y catalán contra otras tantas normas del Ministerio de Agricultura, Pesca y Alimentación, que articulan una serie de medidas para la concesión de ayudas económicas a agricultores y ganaderos, con fondos procedentes del FEOGA-sección Garantía, entendiendo los recurrentes que estas medidas invadían las respectivas competencias exclusivas autonómicas en materia de agricultura y ganadería, al reservarle aquéllas al Estado tanto la tramitación de las solicitudes como la concesión y el pago de las ayudas.

La resolución del TC parte, en primer lugar, de una afirmación de principio ya recogida en sentencias anteriores.

"Ni el Estado ni las Comunidades Autónomas pueden considerar alterado su propio ámbito competencial en virtud de esa conexión comunitaria. La ejecución de los Convenios y Tratados Internacionales en lo que afecte a la competencia de las Comunidades Autónomas no supone, co-

34 Cfr. S.TC 13/1992, fdto. jco. $10^{\circ}$. 
CARLOS I. AYMERICH CANO

mo resulta evidente, atribución de una competencia nueva, distinta de las que en virtud de otros preceptos ya ostenta la Comunidad Autónoma (S.TC 252/1988, fundamento jurídico $2 .^{\circ}$ )" o que "en definitiva, la ejecución del Derecho comunitario corresponde a quien materialmente ostente la competencia según las reglas de Derecho interno, puesto que "no existe una competencia específica para la ejecución del Derecho comunitario" (S.TC 236/1991, fundamento jurídico 9. $\left.{ }^{\circ}\right)$ "35.

que en todo caso es necesario complementar con otro tipo de consideraciones derivadas de la competencia estatal del art. $149.1 .^{\circ} 3^{\mathrm{a}}-$ relaciones internacionales- $y$, especialmente, de la función de garantía por el cumplimiento de los Tratados y Convenios Internacionales a través de los que se le cedan a una organización internacional, competencias derivadas de la Constitución y de garantía también por el cumplimiento de las resoluciones demandas de estas organizaciones, que le atribuye al Estado el art. 93, obligando a una interpretación conjunta de las normas constitucionales y estatutarias atributivas a las CC.AA. de competencia exclusiva en materia de agricultura y ganadería, con éstas otras que asignan al Estado funciones de garantía en materia de relaciones internacionales y respecto de la Comunidad Europea ${ }^{36}$.

Teniendo en cuenta estas consideraciones, el TC subraya que la única diferencia de los conflictos de competencia que resuelve la S.TC 79/1992 y los resueltos en otras ocasiones respecto de ayudas en materia de agricultura y ganadería establecidas por el Estado es que en el caso de aquéllos, los recursos destinados para las ayudas no son aportados por decisión del Estado, sino por decisión de la $\mathrm{CEE}$, que es quien regula su destino, cuantía y condiciones de otorgamiento. Pero y puesto que la CEE - por lo que se refiere al FEOGA-Garantía y de acuerdo con Reglamento CEE 729/1970- mantiene sus relaciones financieras con los Estados miembros, esos fondos se integran en los Presupuestos Generales del Estado, y siendo la competencia estatal discutida no la que ampara esta transferencia de recursos desde el FEOGA-Garantía, sino la que el Estado tiene para articular la gestión y proceder a la ejecución administrativa de esas ayudas comunitarias, resulta que es perfectamente aplicable toda aquella jurisprudencia constitucional relativa a la regulación y gestión de las ayudas consignadas por el Estado en materia de agricultura y ganadería (Ss. TC 95/1986, 96/1986, 101/1988, 145/1989,

35 Cfr. S.TC 79/1992, fdto. jco. $19^{\circ}$.

$36 \mathrm{Cfr}$. sent. cit., fdto. jco. $1 .^{\circ}$ in fine. 
JURISPRUDENCIA

$188 / 1989$ y $13 / 1992$, entre otras) ${ }^{37}$, doctrina a la luz de la cual, como señala el propio Tribunal,

"..se han de resolver los conflictos de competencia planteados, sin perder de vista las peculiaridades de estos casos ni ignorar las exigencias interpretativas y de articulación del ejercicio de las competencias compartidas que resultan del art. 93 CE... 38

La aplicación de esta doctrina general determina que para la gestión de las ayudas, "la Administración territorial ordinaria en el sector de la agricultura y la ganadería debe ser la de las Comunidades Autónomas" 39, a salvo de las reservas de ejecución que a favor del Estado resulten, además de por la aplicación de la doctrina general expuesta, de las peculiaridades de las ayudas del FEOGA que determinan:

- La necesidad de que en relación a algunas ayudas para las que se asigna al Estado español una cifra máxima de ECUs y para evitar que se sobrepase esta cuantía, la resolución de los expedientes de ayuda se encuentre centralizada en un órgano del Estado ${ }^{40}$, ya que en este caso -con los condicionamientos antes dichos- resulta difícil aplicar el principio general de reparto de los fondos entre las CC.AA. competentes 41 establecido en la S.TC 13/1992. Pero esto no supone privar a las CC.AA. del resto de las funciones - recepción de solicitudes, verificación de los datos, tramitación, liquidación o pago de las ayudas y acti-

37 Un resumen de esta doctrina en la S.TC 13/1992 de 6 de febrero, fdto. jco. 4..

$38 \mathrm{Cfr}$., fdto. jco. $2 .^{\circ}$ in fine.

${ }^{39}$ Cfr. S.TC 79/1992, fdto. jco. $4 .^{\circ}$.

$40 \mathrm{Y}$ teniendo en cuenta que el propio TC no desecha la posibilidad de alcanzar ese objetivo por otras vías, puesto que,

"No corresponde a este Tribunal (...) diseñar cuál sea la fórmula precisa preferible para la articulación de las competencias del Estado y de las Comunidades Autónomas en casos en que, como aquí se trata, están abocados a una necesaria colaboración". (Cfr. fdto. jco. 4..$^{\circ}$.

41 El reparto de los fondos, según el TC, podría

"... perjudicar la eficacia plena de la medida que consistiría en la máxima utilización potencial del montante global de los recursos comunitarios asignados al Reino de España para cada tipo de ayuda. O bien se podria resentir la igualdad entre los posibles beneficiarios de las ayudas, que podrian acceder o no a ellas, en igualdad de condiciones, dependiendo del número de solicitudes formuladas en su respectiva Comunidad Autónoma». (S.TC 79/1992, fdto. jco. $4 .^{\circ}$ ). 
vidades de inspección o control- que le corresponden en cuanto titulares de la competencia ejecutiva en la materia.

-Y por lo que se refiere al pago - que algunas de las normas estatales de aplicación de los Reglamentos CEE que establecen las ayudas centralizan en el SENPA-, la conclusión que extrae el Alto Tribunal es la de que siendo éste un acto de ejecución instrumental con relación al acto verdaderamente sustantivo -el de concesión de la ayuda, es decir, el reconocimiento singularizado del derecho a percibirla- no resulta contrario al orden competencial que sea el órgano al que corresponda la decisión el que realice el pago, aunque reconoce que

«...puedan arbitrarse otras fórmulas distintas, sobre cuyo carácter más o menos acertado o ventajoso no corresponde pronunciarse a este Tribunal.» ${ }^{42}$.

${ }^{42} \mathrm{Cfr}$., fdto. jco. $5 .^{\circ}$ in fine. 